this control was distinctly different from the zonal climatic arrangement of to-day, as manifested by the climatic phenomena recorded in Permo-Carboniferous and in Pleistocene times. The greater part of the "plexus of problems of unparallel difficulty" presented in the Permian is involved in the attempts to fit PermoCarboniferous glaciations and the concurrent climatic phenomena to the unproved assumption of solar control. This is true of all glaciations, and of the reglaciations following interglacial warmth which so distinctly contradict solar control that it is difficult to understand why the assumption of solar control has been held with such rigid orthodoxy. Neither critic meets the prime question of a dual versus a solar control of geologic climates.

Marsden Manson

Berkeley, California, OCTOBER 9, 1922

\section{THE EFFECTS OF CAPTIVITY ON A SEX CHARACTER}

LATE last winter I noticed a gravid female in a tank containing European brown trout at the New York Aquarium, and suggested that she be removed and stripped.

As is well known, the males of many salmonidæ, including salmon and most trout, develop a hook on the lower jaw in the breeding season, which is serviceable in their fights at the spawning grounds. Specimens with hooked jaws were therefore selected from the brown trout tank for milt to fertilize the eggs.

Then it was discovered that a hook-jawed individual might be a female. This phenomenon was unknown to us, and as far as we know has never been recorded. But we soon found that we had made no unique discovery, for about the time the brown trout eggs were changing into fry in the hatching troughs, the Aquarium received a visit from Dr. Francis G. Macnaughton of Dunshire, St. Andrews, Scotland, who has experimented largely with European trout. When the writer told him of the females with hooked jaws, he said that in Europe this phenomenon has not infrequently occurred as a result of captivity.

Precisely what effect captivity may have upon the somaplasm to bring about this curious condition, we leave to conjecture; but what a startling biological event it would be if a lioness were to grow a mane and other female animals in captivity developed the secondary sexual characters of the male!

IDA M. MELLEN

\section{The New York AqUarium}

\section{MISUSE OF THE QUESTIONNAIRE}

To THE EpITOR of SCIENCE: A questionnaire is being mailed to "persons whose addresses are given in the book "American Men of Science" to ascertain "what proportion of American men of science are believers in the current religion, what proportion are not," etc. As the questions are in many cases like the famous "Will you leave off beating your mother?" probably the majority of us will ignore them. The bias of the questionnaire is so obvious, it might well be ignored were it not that we shall probably hear before many months that 97 per cent. of American men of science are utterly without religious beliefs, "as shown by a recent careful investigation." Hence I wish to make this early protest against this particular questionnaire and the possibility of drawing any reliable conclusions from the replies received.

OCTOBER 25, 1922

$$
\text { Hubert Lyman Clakk }
$$

\section{QUOTATIONS}

\section{MOTORLESS FLIGHT IN ENGLAND}

THE French airman, M. Maneyrolle, won the prize of $£ 1,000$ offered by the Daily Mail, by a wind flight on October 21 lasting three hours and twenty-two minutes. The notable successes registered during the recent French contests, and especially during the German contests, raised the question whether British fliers could rival the feats of their foreign colleagues, and the offer of a prize of $£ 1,000$ by the Daily Mail led to the organization, at Itford Hill and Firle Beacon on the South Downs, of the first British gliding contests since the war, which commenced on October 16 and continued through the week. Additional prizes were offered by the Royal Aero Club and others. The entry of British machines and pilots was 